\title{
Capsular contracture by silicone breast implants: possible causes, biocompatibility, and prophylactic strategies
}

This article was published in the following Dove Press journal:

Medical Devices: Evidence and Research

29 November 2013

Number of times this article has been viewed

\section{Andreas E Steiert \\ Maria Boyce \\ Heiko Sorg}

Department of Plastic, Hand and Reconstructive Surgery, Hannover Medical School, Hannover, Germany
Correspondence: Andreas E Steiert Department of Plastic, Hand and Reconstructive Surgery, Hannover Medical School, Carl-Neuberg-Str I, 30625 Hannover, Germany

$\mathrm{Tel}+495 \mathrm{II} 5320$

Fax +49 5II 5328890

Email steiert.andreas@mh-hannover.de

\begin{abstract}
The most common implanted material in the human body consists of silicone. Breast augmentation and breast reconstruction using silicone-based implants are procedures frequently performed by reconstructive and aesthetic surgeons. A main complication of this procedure continues to be the development of capsular contracture (CC), displaying the result of a fibrotic foreign body reaction after the implantation of silicone. For many years, experimental and clinical trials have attempted to analyze the problem of its etiology, treatment, and prophylaxis. Different theories of CC formation are known; however, the reason why different individuals develop $\mathrm{CC}$ in days or a month, or only after years, is unknown. Therefore, we hypothesize that CC formation, might primarily be induced by immunological mechanisms along with other reasons. This article attempts to review CC formation, with special attention paid to immunological and inflammatory reasons, as well as actual prophylactic strategies. In this context, the word "biocompatibility" has been frequently used to describe the overall biological innocuousness of silicone in the respective studies, although without clear-cut definitions of this important feature. We have therefore developed a new five-point scale with distinct key points of biocompatibility. Hence, this article might provide the basis for ongoing discussion in this field to reduce singlepublication definitions as well as increase the understanding of biocompatibility.
\end{abstract}

Keywords: biofilm, foreign body reaction, breast augmentation, biocompatibility, fibrosis

\section{Introduction}

The use of silicone for breast implants is a story of ups and downs that has been described in detail in many articles. ${ }^{1-7}$ The implantation of silicone-based implants for breast reconstruction or augmentation is still one of the procedures most commonly performed by reconstructive and aesthetic surgeons. Approximately 1.5 million units are sold per year by the world's leaders in the market for the production of silicone breast implants. The main potential complications after silicone breast implantation have shown to be breast implant failure by rupture, distortion, or leakage; capsular fibrosis and contracture; silicone gel bleeding and spreading throughout the organism; chronic inflammation around the silicone implant; and potential carcinogenicity of foreign implants. ${ }^{2,4,5-8-10}$ The development of capsular contracture (CC; Table 1, Figure 1) occurs at a rate of up to $80 \%$, as previously shown in a review article by Berry et al, ${ }^{11}$ and is therefore a severe problem for patients. Hence, CC formation is the basis of many scientific studies hoping to understand, prevent, or treat its development. However, the cause for $\mathrm{CC}$ formation is still not entirely clear and seems to have a multifactorial genesis. In a literature review, we found that the word "biocompatibility" is a frequently used term. ${ }^{3,12-23}$ A Medline search using "biocompatibility" retrieved 
Table I Stages of capsular fibrosis after breast augmentation

\begin{tabular}{ll}
\hline Stage & Palpation \\
\hline Baker I & Breast is soft; implant is not palpable \\
Baker II & Breast is solid; implant is palpable but not visible \\
Baker III & Breast is hardened; implant is palpable and visible \\
Baker IV & Breast is hard, deformed, and painful; implant is palpable \\
& and clearly visible
\end{tabular}

Note: Classification on capsular fibrosis after breast augmentation introduced by Baker. $^{73}$

13,536 hits in July 2013 , including results from nearly every medical field. Notably, the use of this word seemed to be a popular way of describing the biological innocuousness of implanted foreign material, especially silicone, in the human body. In the published results, the respective groups used their own definitions of biocompatibility, as can be seen in Table 2 . From this point of view, biocompatibility is a very important issue, especially as technical innovations are available and could be implanted into the organism. However, technical progress develops much faster than tissue engineering, and therefore there is a need for a clear-cut description of biocompatibility for research, as well as clinical purposes, to unify the scientific language (Table 2).

This article reviews $\mathrm{CC}$ formation with special attention paid to immunological and inflammatory mechanisms. It further provides a proposal for a new start up-point for the ongoing discussion by presenting a new distinct five-point scale, which will better address and, in particular, simplify general issues of biocompatibility in clinical application.

\section{Capsular contracture}

In the last decades, millions of people have been exposed to various forms of silicone. Silicone's chemical structure and the
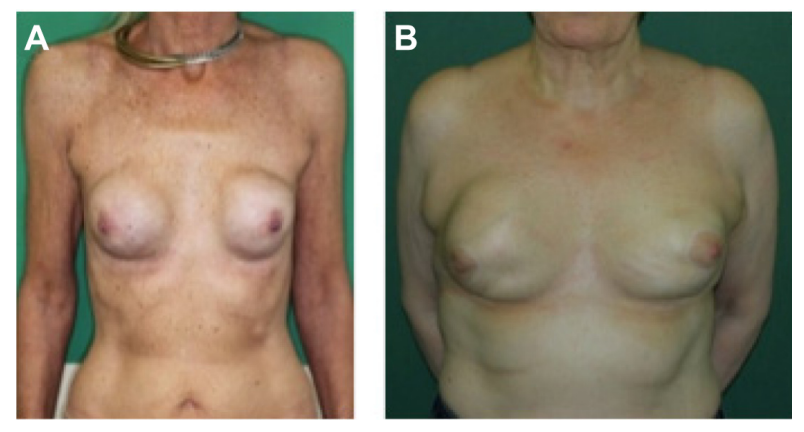

Figure I Representative images of two patients suffering from severe capsular contracture after silicone breast implantation.

Notes: (A) A 54-year-old lady with a history of disseminated mamma cysts followed by mastectomy on both sides. The reconstructive breast augmentation was performed 10 years before she presented with painful capsular contracture at both breasts according to Baker stage IV. (B) A 70-year-old lady with a history of fibrous breast adenomas and familial breast cancer. In 1981, she received a subcutaneous mastectomy with a I-year-later reconstruction by silicone breast implants, and an implant change 10 years later. Now, she has again presented with capsular contracture according to Baker Stage III-IV.
Table 2 Exemplary citations for the description or definition of the word biocompatibility

\begin{tabular}{|c|c|}
\hline Authors & Biocompatibility \\
\hline Ziats et al ${ }^{18}$ & $\begin{array}{l}\text { After implantation of a biomaterial, the responses that } \\
\text { occur at the interface of the implanted material and in } \\
\text { the surrounding environment are important events in } \\
\text { determining the biocompatibility of the implant. }\end{array}$ \\
\hline $\begin{array}{l}\text { Anderson } \\
\text { et } \mathrm{al}^{12}\end{array}$ & $\begin{array}{l}\text { The biocompatibility of implanted biomaterials is } \\
\text { determined by the degrees to which host homeostatic } \\
\text { mechanisms are perturbed during surgical placement } \\
\text { of the implant and the extents to which pathological } \\
\text { consequences are created from the ensuing } \\
\text { inflammatory, wound healing, and foreign body } \\
\text { responses to surgical injury. }\end{array}$ \\
\hline Plenk $\mathrm{Jr}^{17}$ & $\begin{array}{l}\text { Therefore, "biocompatibility" is now only vaguely } \\
\text { defined as "the ability of a material to perform } \\
\text { with an appropriate host response in a specific } \\
\text { application." }\end{array}$ \\
\hline $\begin{array}{l}\text { Laschke } \\
\text { et } \mathrm{al}^{71}\end{array}$ & $\begin{array}{l}\text { However, a riskless and successful use of such } \\
\text { devices in clinical practice is only possible if they } \\
\text { exhibit an adequate biocompatibility. This means that } \\
\text { they should not induce a severe local or systemic } \\
\text { inflammatory reaction. }\end{array}$ \\
\hline $\begin{array}{l}\text { Helmus } \\
\text { et al }{ }^{69}\end{array}$ & $\begin{array}{l}\text { In fact, next-generation medical devices will } \\
\text { require enhanced biocompatibility by using, for } \\
\text { example, pharmacological agents, bioactive coatings, } \\
\text { nanotextures, or hybrid systems containing cells that } \\
\text { control biologic interactions to have desirable biologic } \\
\text { outcomes. }\end{array}$ \\
\hline Williams $^{72}$ & $\begin{array}{l}\text { It is shown that, in the vast majority of circumstances, } \\
\text { the sole requirement for biocompatibility in a medical } \\
\text { device intended for long-term contact with the tissues } \\
\text { of the human body is that the material shall do no } \\
\text { harm to those tissues, achieved through chemical and } \\
\text { biological inertness. }\end{array}$ \\
\hline
\end{tabular}

many changes since its launch have also raised many problems and questions about its local, as well as systemic, interactions. ${ }^{6} \mathrm{CC}$ formation displays the result of a fibrotic foreign body reaction after implantation of silicone breast prostheses in the human body. ${ }^{6,7,10,24-26}$ This physiological reaction of the body to the silicone implant, forming a fibrous capsule, reflects two sides of a coin: on the one hand, it maintains the correct positioning of the implant, but on the other hand, it is associated with pain, hardening, tightness, deformity, and distortion of the breast. Furthermore, capsular fibrosis is the number one reason for revision operations, especially in implant exchange procedures, as capsular fibrosis does not occur that frequently in primary augmentations compared with in reconstruction/revision procedures. ${ }^{27,28}$ The formation of a fibrous capsule is part of a process of protection of the organism from foreign material, which can be formed within $1-2$ weeks postoperatively. ${ }^{9}$ The myofibroblast displays one of the predominant cell types of the capsule, however, 
and is accompanied by macrophages, polymorphonuclear leukocytes, lymphocytes, plasma cells, and mast cells. ${ }^{29-31}$ The capsule thickness consists of approximately $27 \%$ myofibroblasts, with increasing tensile strength according to the degree of contracture. ${ }^{32}$ Interestingly, this is not correlated with the number of fibroblasts. ${ }^{32}$ The cellular source of the myofibroblast seems to be the bone marrow, as shown by Isom et al, who found $25 \%$ of bone marrow-derived stem cells in textured silicone shells in mice. ${ }^{33}$ Prantl et al further demonstrated that capsular thickness was associated with the number of silicone particles and silicone-loaded macrophages in the peri-implant capsule and with an increased local inflammatory reaction. ${ }^{30,34}$ These histological findings, which were classified by the Wilflingseder score, ${ }^{35}$ correlated well with the clinical Baker classification (Table 1, Figure 1). In addition, it could be demonstrated that serum hyaluronan levels, ${ }^{29}$ as well as circulating immune complexes, procollagen III, antipolymer antibodies, and soluble intercellular adhesion molecule 1 (sICAM-1), ${ }^{36}$ were significantly elevated in patients with $\mathrm{CC}$, also correlating in part with the clinical Baker stage of contracture. ${ }^{29}$ After multiple experimental and clinical trials, there seems to be a strong consensus that the use of textured outer shell surfaces, in comparison with smooth surfaces, is able to decrease the incidence of $\mathrm{CC}$ by disrupting contractile forces around the implant, ${ }^{28,37-42}$ emphasizing the need for better physical properties than cellular or pharmacological strategies of contracture formation.

In the following text, we highlight recent experimental studies dealing with different issues thought to induce, prevent, reduce, or treat capsular fibrosis and contracture around silicone breast implants.

\section{Immunological mechanisms}

The criteria, which finally lead to integration or rejection of foreign material in the human organism, are multifaceted; however, we think immunological mechanisms play a major role in the development of CC. Therefore, research on different immunological reactions and mechanisms displays a starting point for potential preventive strategies. It was Ojo-Amaize et $\mathrm{al}^{43}$ in a blinded cross-sectional study, who determined that women with symptomatic implanted as well as explanted silicone breast implants had twice as much abnormal silicone-specific T-cell responses as women with no symptoms. Further analysis demonstrated that these cells are $\mathrm{CD}^{+}$, whereas the $\mathrm{CD}^{+} \mathrm{T}$-cell population did not contribute to this activity. ${ }^{43}$ Ciapetti et al also showed that peripheral blood lymphocytes of patients with silicone implants had a significantly increased rate of proliferation and viability when these cells have been re-exposed to silicone in vitro. Interestingly, there was an even more significant difference between lymphocytes of aesthetic, in comparison with reconstructive, patients. ${ }^{19}$ Two working groups, however, mainly contributed in detail on this issue. First, Smalley et al confirmed that patients with silicone implants are prone to an exaggerated T-cell-mediated immune reactivity, as given by an 18-fold higher stimulation index of stimulated lymphocytes of implant patients than of nonimplant control patients. ${ }^{44}$ In an ongoing study, Smalley et al could further demonstrate that the T-cell activation by silicone depends on monocytes. ${ }^{45}$ The second group, led by Dolores Wolfram, studied the activity of immunological and inflammatory processes that might be involved in CC formation, focusing on immune cells, proteins of the extracellular matrix, stress proteins, and adhesion molecules. ${ }^{22}$ The highest activity could be seen in the interface of the silicone implant and the formed fibrous capsule or in its direct adjacency, where activated $\mathrm{CD}^{+}$T-cells, macrophages, and Langerhans-celllike dendritic cells could be detected. Furthermore, the tissue specimen showed intense positive staining of fibronectin on the interface, likely mediating interactions between the silicone and macrophages, fibroblasts, and T-cells. ${ }^{22}$ To determine the specificity and function of these T-lymphocytes, Wolfram et al investigated the interplay of T-cells and their cytokine profile in capsular fibrosis. ${ }^{22}$ First, they verified that intracapsular lymphocytes were predominantly $\mathrm{CD}^{+}$ cells producing a specific profibrotic cytokine profile, which mediates the local immune response by means of activated TH1/TH17-cells. As the intracapsular T-cell ratio has been inversely proportional to the clinical stage of fibrosis, it has been hypothesized that profibrotic cytokines and growth factors stimulate capsular fibrosis in the retention of local regulatory T-cells. ${ }^{22,46}$

\section{Biofilm in capsular contracture}

Infections are the leading cause of morbidity after breast augmentation, as proposed by Pittet et al. ${ }^{10}$ Here, the degree of CC seems to be associated with a prolonged or accelerated inflammatory process. ${ }^{10,47-50}$ This inflammatory process might be exaggerated by local factors such as hematoma or infection, or even by an invasion from remote-to-implant, which further increases the degree of inflammation, finally leading to fibrosis. ${ }^{51-54}$ The development of a septic biofilm at the time of implantation or within the first minutes to hours, and the subclinical infection of the foreign material, especially with Stapyhlococcus epidermidis and Propionibacterium acnes, is described by many authors as having a strong effect on the 
formation of CC. . $^{10,51,52,55-57}$ However, the word "biofilm" is used in many different ways. Our understanding of a biofilm is that a certain liquid film results after the implantation of foreign material, which surrounds the respective device and can be described as a sterile or aseptic biofilm. This biofilm displays the interface between the foreign material and the organism, consisting of different chemoattractants and cytokines, which decide either to activate a foreign body response with inflammation or to tolerate the material and integrate it into the body's homeostasis. Therefore, it will be the surface of the implanted material, in close association with the existing sterile biofilm, which will individually determine the next steps of reaction and which cells might be involved. An exceptional example for a septic biofilm displays the implantation of foreign material into the oral cavity, as it is intentionally implanted in a bacterially contaminated area. In this case, the evolving liquid film is septic and must therefore be differentiated as a septic biofilm. ${ }^{58-63}$ In all other cases, the respective sterile biomaterial is implanted in sterile pockets, resulting in an aseptic biofilm by definition.

In the context of silicone breast implantation, one should also consider that the human breast region is not a sterile anatomic structure, as it has physiologic or even pathologic bacterial skin flora derived from the nipple ducts. ${ }^{10}$ The highest incidence of capsular fibrosis seems to occur when the silicone implant has been placed in a subglandular position via a periareolar approach through the mammary gland, leading to $S$. epidermidis in the ductal tissue. ${ }^{64}$ In addition, it has been shown that subclinical bacterial colonization plays a pivotal role in the development of high-grade $\mathrm{CC}$ (Baker III/IV; Table 1), as colonization could be detected in $66.7 \%$ of explanted contractures, whereas low-grade contractures (Baker I/II; Table 1) did not show any colonization at all. ${ }^{55}$ There is also a positive linear correlation between the severity of the contracture and the local inflammatory reaction. ${ }^{55,65}$ To analyze this problem further, several authors and groups evaluated different experimental models and therapeutic strategies. ${ }^{66-68}$ Tamboto et al developed a new in vivo pig model in which female animals underwent augmentation mammaplasty, using miniature gel-filled implants and pocket inoculation with $S$. epidermidis. ${ }^{66}$ The main outcome parameters have been clinical Baker grade (Table 1) and further laboratory testing of the resected capsules 13 weeks after implantation. This group could demonstrate that the presence of a septic biofilm results in subclinical infection and was associated with a fourfold increase of subsequent contracture formation. Interestingly, even noninoculated pockets also developed contracture caused by the native porcine $S$. epidermidis. ${ }^{66}$ To prevent bacterial colonization, several studies tried to administer local antiseptic washing or systemic antibiotics; however, it had only minor effects. ${ }^{52,67,68}$ Coating or impregnation with antimicrobial substances might therefore be an alternative possibility to reduce, but not prevent, capsular fibrosis formation. Unlu et al tested the effect of rifampin in the implant pocket, as well as the topical administration on the implants in an in vivo rat model. ${ }^{68}$ The authors observed that the thickness of the peri-implant fibrous capsule could be significantly reduced by rifampin after 12 weeks, with no difference between topical or local administration of the antibiotic. ${ }^{68}$

Infection is without question a disruptive factor for the biocompatibility of silicone. The use of antibiotic substances might reduce, but surely not prevent, the formation of $\mathrm{CC}$ as a unifactorial mechanism. Therefore, we think biocompatible products are not defined by the absence of a septic infection alone.

\section{Prophylactic strategies of capsular contracture}

To prevent the formation of capsular fibrosis formation, several different approaches might be possible. However, sophisticated methods tested in vitro or in animal models cannot be easily transferred to the human organism. In the management of prophylactic strategies, the modulation of the implant surface texture and its patterning with different substances seems to be one actual idea to solve this problem. ${ }^{23}$ For this, the cell-to-surface interaction needs to be better understood to engineer suitable materials for implantation. Using different microscopic techniques, Barr et al investigated the cytoskeletal reaction of fibroblasts to silicone surfaces. ${ }^{15}$ The results of this study revealed different possible reasons for the development of CC. It was shown that the smooth surface of implants predisposes the planar arrangement of the fibroblast around the implant. Interestingly, the macroscopically smooth-surface implant also presents with a rippled microscopic texture on the surface, which might increase the formation of a synovialtype epithelium, experienced in fibrotic breast capsules. ${ }^{16}$ Textured implant surfaces are able to decrease the formation of contracture, as the fibroblast anchors into the deep and random pattern; hence, the fibroblast might not be able to align planarly. ${ }^{16}$ Therefore, the authors concluded that cells might directly react to the topography of the biomaterial. However, a shortcoming of this study is that the authors only presented microscopic images of the surfaces without the cultivation of fibroblasts. This information has been published 
in an ongoing study by Barr et al, in which the cytoskeletal reaction of breast tissue-derived human fibroblasts to silicone was investigated..$^{15}$ The authors show it is possible to create different topographies of silicone surfaces, which are able to induce a directional growth of fibroblasts as well as alterations in cell shape and their phenotype. The used fibroblasts have been able to detect the respective surface topography made of different widths and depths of ridges, pits, and pillars inducing contact guidance or orientation for the cells. The authors therefore concluded that the production of more biocompatible implants is possible via a change of the surface topography on which the fibroblasts attach.

In our opinion, however, biocompatibility is not described by the better or worse growth of fibroblasts on certain topography. Fibroblasts lead the way for the development of fibrosis, finally resulting in exactly the complication that should be prevented. Therefore, the fibroblast should neither be attracted to nor able to enter the vicinity of the implant from the very beginning after implantation, which would induce the known foreign body reaction, finally leading to $\mathrm{CC}$ formation.

\section{Capsular contracture formation: outlook and vision}

Medical, pharmaceutical, and material sciences analyze existing concepts and develop potential new ideas in silicone breast implantation. All interventions aim at the optimization of implant integration into the surrounding tissues, as well as at the prevention of contracture. These include surface texture changes, drug solutions, and careful surgical techniques; however, all have only limited success. In this context, there are many unsolved problems that seem to be directly associated with biocompatibility. A main goal in silicone breast implantation is the complete tolerance and integration of the foreign material into the human body without any remote-toimplant effects. The interface between the implant surface and the implant pocket might therefore be of great interest. In this case, the implant material should be functionalized to integrate it and to consecutively reduce the rate of complications. Furthermore, as Helmus already proposed, it seems to be the focus to integrate biocompatibility into the device and not vice versa. ${ }^{69}$ For example, Barr et al studied the behavior of fibroblasts on different silicone physical structures, concluding there is a need for surface modernization to develop more "biocompatible" constructs. ${ }^{15,16}$ However, Barr et al does not give an answer on how the fibroblast participates in biocompatibility. The question arises of whether the development of $\mathrm{CC}$ represents a nonbiocompatible reaction of the human organism to the silicone implant. In the prevention of $\mathrm{CC}$, we think the fibroblast should not be involved at all, by preventing its adherence and interaction on the interface.

Taken together, in the line of the above-mentioned underlying mechanisms and ideas, we felt it cannot be clearly stated what seems to be biocompatible and what is not. For this reason, there is an urgent need for a precise definition as well as for the introduction of clear-cut categories of biocompatibility for implanted materials, as well as tissues and organs. Thus, we thought to provide a solid basis for the ongoing research by defining distinct key points of biocompatibility. We have therefore developed a new five-point scale with respective criteria, which better addresses this problem in general (Figure 2). This classification system might be used as a clear, unambiguous, and simple instrument for researchers and manufacturers in material science, as an identification mark for the quality of biocompatibility of their devices and products; for doctors, in their clinical routine, to address the actual level of biocompatibility after the respective material/organ/tissue implantation; and, of course, for patients, who should know the biocompatibility of the respective implanted device and the potential complications to best monitor the function of their implant. This classification, however, is flexible in its use, especially when it comes to clinical aspects, where the level might have to be adjusted with clinical progress.

\section{Level A}

The highest level of biocompatibility is displayed by a full integration of the implant (material/organ/tissue) into the human body, as might be seen in human leukocyte antigen (HLA)-identical organ transplantation without the need for any immunosuppressive therapy, resulting in an undisturbed biological function of the respective organ or tissue. The organism will not identify these materials as foreign. As a consequence, an immunological reaction cannot be seen at all, and the implant will be fully integrated into the human body without any difficulty. The A level might further ensure the often-given lifetime warranty of implantable devices by the industry. Level A grading displays full biocompatibility with complete integration into the organism or $100 \%$ resorption without residues (Table 3 ).

\section{Level B}

The second level of biocompatibility is described by an incorporation or acceptance of the implant, but with a need for a specific drug therapy to reduce the complications that might arise. This combination results in an acceptable coexistence of the implant in the human body's homeostasis. For example, this can be seen in every non-HLA-identical transplanted organ in which immunosuppressive therapy has to be carried 


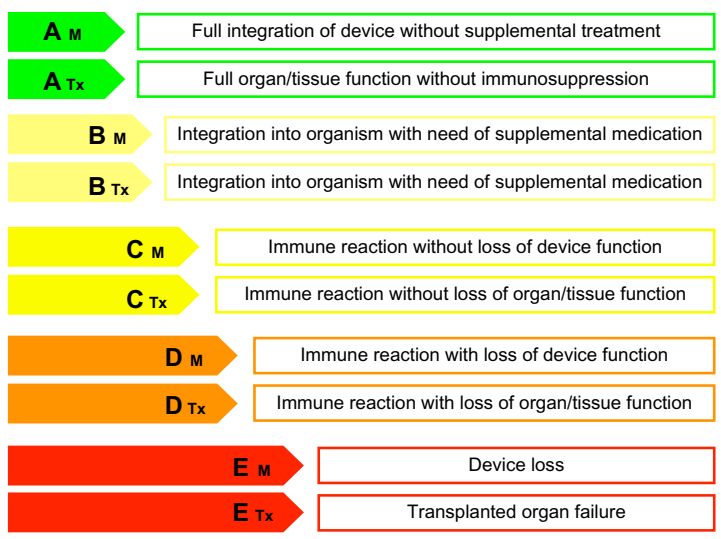

Figure 2 Grades of biocompatibility according to their potential of acceptance by the (human) organism.

Note: The differentiation $M$ and $T x$ further classifies the implantation of foreign material or device (M) or biological tissues (Tx).

out over a lifetime. In the case of stem cell transplantation, however, this switches to an A level, as immunosuppressive therapy can be terminated after several months. As a further example, the implantation of vascular stents usually results in the recommendation for anticoagulation therapy with acetylsalicylic acid, which is synonymous with B-level biocompatibility (Table 3 ).

\section{Level C}

Level $\mathrm{C}$ biocompatible implants are every implanted device or tissue that will be recognized by the body as foreign and will induce an immune reaction. This reaction, however, does not adversely affect the respective tissue or organ function immediately, and thus represents a tolerated material. Baker stages I and II (Table 3) display an example of level $\mathrm{C}$ material; however, this might change to a $\mathrm{D}$ level in progressive fibrosis. A further example might be the absorption of implanted foreign materials such as polysiloxane or polyglactin sutures.

\section{Level D}

In this level, the implant is recognized as foreign by an immune reaction; however, this reaction is acutely or chronically associated with a loss of function. This category would actually fit for silicone breast implants, especially in Baker III-IV stages (Table 3). Another example is an implanted vascular graft or shunt, which might be occluded as a result of the foreign surface or exaggerated fibrotic reaction. Furthermore, in cochlear implant surgery, there occurs the problem of correct connection of the implanted electrodes by time, as developing fibrotic tissue hinders the correct function.
Table 3 Examples for the use of the newly introduced levels of biocompatibility

\begin{tabular}{ll}
\hline Materials & Organs/tissues \\
\hline A & \\
- Not yet available & $\begin{array}{c}\text { - Human leukocyte antigen-identical organ/ } \\
\text { tissue transplantation (kidney, split liver) }\end{array}$ \\
B & Cornea transplantation \\
- Drug-eluting stent & - Non-human leukocyte \\
implantation & antigen-identical organ/tissue \\
- Mechanic heart valve & transplantation (heart, lung, pancreas) \\
C & - Vascular homografts (anticoagulation) \\
- Silicone (Baker I-II) & - Secondary malignancies resulting from \\
- Granuloma induced & immunosuppressive therapy \\
by polydioxan or & - Adverse effects of anticoagulation \\
polyglactin sutures & - Adverse effects of immunosuppression \\
D & \\
- Silicone (Baker (III-IV)) & - Acute graft versus host disease \\
- Stent narrowing & - Chronic graft versus host disease \\
- Reduced function & \\
of cochlear implant & \\
E & \\
- Device loss & - Transplanted organ failure \\
- Stent thrombosis & \\
\hline
\end{tabular}

\section{Level E}

The classical signs of inflammation (calor, rubor, dolor, tumor) define an acute rejection of the implanted material shortly after implantation, leading to further treatment or even worsening of the respective organ or tissue function and explantation of the device. As a prime example, this is seen in graft versus host reactions after stem cell transplantation; however, it might also be reversible to an upgrading to D or $\mathrm{C}$ level by the introduction of the respective therapy. E levels further describe materials or tissues, which induce adverse remote-to-implant or teratogenic effects.

\section{Conclusion}

Without a doubt, the invention of implantable silicones for either reconstructive or aesthetic purposes represents a great opportunity to increase the quality of life of many patients. However, it is also accompanied by many problems the implant wearer might get confronted with. It is the task of medicine to perform excellent but particularly meaningful research to prevent physical as well as psychological harm to our patients. ${ }^{70}$ Therefore, we need up-to-date research based on a clear and international understandable definition. The launch of new material components; smaller and better working solutions; and more sophisticated computerized applications to restore body functions show that technical progress cannot be slowed down. 
The authors of this manuscript are convinced that the launch of new technical innovations will continue to progress rapidly, and restoration of the respective tissue or organ function by means of the organism itself (ie, tissue engineering or stem cell differentiation) might be possible. However, synthetic material, similar to HLA-identical organ transplantation does not exist (Table 3). Therefore, it is not comprehensible why foreign materials and devices are not implanted in to the human body with higher frequency, as long as the biological regeneration is not adequately able to restore the respective organ or tissue functions. The here-introduced new levels better address the general issues of biocompatibility in the human organism in general, and therefore simplify understanding of the term in ongoing material and transplantation research, as well as its application as a clinical marker for all involved individuals. Thus, this article might represent the basis for the ongoing discussion and also for a consensus finding in this field to reduce single-publication definitions and increase attempts to unify the scientific language.

\section{Disclosure}

The authors report no conflicts of interest in this work.

\section{References}

1. Spear S. The breast implant story. Ann Plast Surg. 2006;56(5): 573-583.

2. Gampper TJ, Khoury H, Gottlieb W, Morgan RF. Silicone gel implants in breast augmentation and reconstruction. Ann Plast Surg. 2007;59(5):581-590.

3. Berry MG, Davies DM. Breast augmentation: Part I - A review of the silicone prosthesis. J Plast Reconstr Aesthet Surg. 2010;63(11): 1761-1768.

4. Hajdu SD, Agmon-Levin N, Shoenfeld Y. Silicone and autoimmunity. Eur J Clin Invest. 2011;41(2):203-211.

5. Zuckerman DM. Reasonably safe? Breast implants and informed consent. Reprod Health Matters. 2010;18(35):94-102.

6. Daniels AU. Silicone breast implant materials. Swiss Med Wkly. 2012;142:w13614.

7. Puskas JE, Luebbers MT. Breast implants: the good, the bad and the ugly. Can nanotechnology improve implants? Wiley Interdiscip Rev Nanomed Nanobiotechnol. 2012;4(2):153-168.

8. Gerszten PC. A formal risk assessment of silicone breast implants. Biomaterials. 1999;20(11):1063-1069.

9. Goldberg EP. Silicone breast implant safety: physical, chemical, and biologic problems. Plast Reconstr Surg. 1997;99(1):258-261.

10. Pittet B, Montandon D, Pittet D. Infection in breast implants. Lancet Infect Dis. 2005;5(2):94-106.

11. Berry MG, Cucchiara V, Davies DM. Breast augmentation: Part II Adverse capsular contracture. J Plast Reconstr Aesthet Surg. 2010;63(12): 2098-2107.

12. Anderson JM, McNally AK. Biocompatibility of implants: lymphocyte/macrophage interactions. Semin Immunopathol. 2011;33(3): 221-233.

13. Binnebösel M, von Trotha KT, Jansen PL, Conze J, Neumann UP, Junge K. Biocompatibility of prosthetic meshes in abdominal surgery. Semin Immunopathol. 2011;33(3):235-243.

14. Werner L. Biocompatibility of intraocular lens materials. Curr Opin Ophthalmol. 2008;19(1):41-49.
15. Barr S, Hill E, Bayat A. Patterning of novel breast implant surfaces by enhancing silicone biocompatibility, using biomimetic topographies. Eplasty. 2010;10:e31.

16. Barr S, Hill E, Bayat A. Current implant surface technology: an examination of their nanostructure and their influence on fibroblast alignment and biocompatibility. Eplasty. 2009;9:e22.

17. Plenk $H$ Jr. The role of materials biocompatibility for functional electrical stimulation applications. Artif Organs. 2011;35(3):237-241.

18. Ziats NP, Miller KM, Anderson JM. In vitro and in vivo interactions of cells with biomaterials. Biomaterials. 1988;9(1):5-13.

19. Ciapetti G, Granchi D, Stea S, et al. Assessment of viability and proliferation of in vivo silicone-primed lymphocytes after in vitro re-exposure to silicone. J Biomed Mater Res. 1995;29(5):583-590.

20. European Commission DG Enterprise Directorate G Unit 4 - Pressure Equipment, Medical Devices, Metrology. Guidelines for Conformity Assessment of Breast Implants According to Directive 93/42/EEC Relating to Medical Devices. 1998. Available from: http://ec.europa.eu/ health/medical-devices/files/meddev/2_5-7_07-1998_en.pdf. Accessed October 11, 2013.

21. Bassetto F, Scarpa C, Caccialanza E, Montesco MC, Magnani P. Histological features of periprosthetic mammary capsules: silicone vs polyurethane. Aesthetic Plast Surg. 2010;34(4):481-485.

22. Wolfram D, Rainer C, Niederegger H, Piza H, Wick G. Cellular and molecular composition of fibrous capsules formed around silicone breast implants with special focus on local immune reactions. J Autoimmun. 2004;23(1):81-91.

23. Steiert A, Reimers K, Burke W, Zapf A, Vogt P. Covalent vectored binding of functional proteins by bifunctional crosslinking at silicone interfaces. J Biomed Mater Res A. 2012;100(5):1248-1255.

24. Embrey M, Adams EE, Cunningham B, Peters W, Young VL, Carlo GL. Factors associated with breast implant rupture: pilot of a retrospective analysis. Aesthetic Plast Surg. 1999;23(3):207-212.

25. Iwuagwu F. Silicone Breast Implants: Complications. Symposium on Aesthetic Surgery of the Breast, Owsley JQ Jr, Peterson RA, editors. St Louis, MO: CV Mosby Co; 1978;344-352.

26. Schaub TA, Ahmad J, Rohrich RJ. Capsular contracture with breast implants in the cosmetic patient: saline versus silicone - a systematic review of the literature. Plast Reconstr Surg. 2010;126(6): 2140-2149.

27. Handel N, Cordray T, Gutierrez J, Jensen JA. A long-term study of outcomes, complications, and patient satisfaction with breast implants. Plast Reconstr Surg. 2006;117(3):757-767.

28. Handel N, Jensen JA, Black Q, Waisman JR, Silverstein MJ. The fate of breast implants: a critical analysis of complications and outcomes. Plast Reconstr Surg. 1995;96(7):1521-1533.

29. Prantl L, Pöppl N, Horvat N, Heine N, Eisenmann-Klein M. Serologic and histologic findings in patients with capsular contracture after breast augmentation with smooth silicone gel implants: is serum hyaluronan a potential predictor? Aesthetic Plast Surg. 2005;29(6):510-518.

30. Prantl L, Schreml S, Fichtner-Feigl S, et al. Clinical and morphological conditions in capsular contracture formed around silicone breast implants. Plast Reconstr Surg. 2007;120(1):275-284.

31. Coleman DJ, Sharpe DT, Naylor IL, Chander CL, Cross SE. The role of the contractile fibroblast in the capsules around tissue expanders and implants. Br J Plast Surg. 1993;46(7):547-556.

32. Hwang K, Sim HB, Huan F, Kim DJ. Myofibroblasts and capsular tissue tension in breast capsular contracture. Aesthetic Plast Surg. 2010;34(6): 716-721.

33. Isom C, Kapoor V, Wilson L, et al. Breast implant capsules are partially composed of bone marrow-derived cells. Ann Plast Surg. 2007;58(4): 377-380.

34. Prantl L, Schreml S, Fichtner-Feigl S, et al. [Histological and immunohistochemical investigations with capsular contracture after breast augmentation with smooth silicone gel implants.] Handchir Mikrochir Plast Chir. 2006;38(4):224-232. German.

35. Wilflingseder P, Hoinkes G, Mikuz G. Tissue reactions from silicone implant in augmentation mammaplasties. Minerva Chir. 1983;38(12): $877-880$. 
36. Wolfram D, Oberreiter B, Mayerl C, et al. Altered systemic serologic parameters in patients with silicone mammary implants. Immunol Lett. 2008;118(1):96-100.

37. Ulrich D, Ulrich F, Pallua N, Eisenmann-Klein M. Effect of tissue inhibitors of metalloproteinases and matrix metalloproteinases on capsular formation around smooth and textured silicone gel implants. Aesthetic Plast Surg. 2009;33(4):555-562.

38. Collis N, Coleman D, Foo IT, Sharpe DT. Ten-year review of a prospective randomized controlled trial of textured versus smooth subglandular silicone gel breast implants. Plast Reconstr Surg. 2000;106(4):786-791.

39. Wong CH, Samuel M, Tan BK, Song C. Capsular contracture in subglandular breast augmentation with textured versus smooth breast implants: a systematic review. Plast Reconstr Surg. 2006;118(5):1224-1236.

40. Malata CM, Feldberg L, Coleman DJ, Foo IT, Sharpe DT. Textured or smooth implants for breast augmentation? Three year follow-up of a prospective randomised controlled trial. Br J Plast Surg. 1997;50(2): 99-105.

41. Coleman DJ, Foo IT, Sharpe DT. Textured or smooth implants for breast augmentation? A prospective controlled trial. Br J Plast Surg. 1991;44(6):444-448.

42. Hakelius L, Ohlsén L. Tendency to capsular contracture around smooth and textured gel-filled silicone mammary implants: a five-year followup. Plast Reconstr Surg. 1997;100(6):1566-1569.

43. Ojo-Amaize EA, Conte V, Lin HC, Brucker RF, Agopian MS, Peter JB. Silicone-specific blood lymphocyte response in women with silicone breast implants. Clin Diagn Lab Immunol. 1994;1(6):689-695.

44. Smalley DL, Shanklin DR, Hall MF, Stevens MV, Hanissian A. Immunologic stimulation of $\mathrm{T}$ lymphocytes by silica after use of silicone mammary implants. FASEB J. 1995;9(5):424- 427.

45. Smalley DL, Shanklin DR, Hall MF. Monocyte-dependent stimulation of human T cells by silicon dioxide. Pathobiology. 1998;66(6): 302-305.

46. Momoh AO, Chung KC. Discussion. T regulatory cells and TH17 cells in peri-silicone implant capsular fibrosis. Plast Reconstr Surg. 2012;129(2):338e-339e

47. Khan UD. Breast augmentation, antibiotic prophylaxis, and infection: comparative analysis of 1,628 primary augmentation mammoplasties assessing the role and efficacy of antibiotics prophylaxis duration. Aesthetic Plast Surg. 2010;34(1):42-47.

48. Burkhardt BR, Fried M, Schnur PL, Tofield JJ. Capsules, infection, and intraluminal antibiotics. Plast Reconstr Surg. 1981;68(1):43-49.

49. De Cholnoky T. Augmentation mammaplasty. Survey of complications in 10,941 patients by 265 surgeons. Plast Reconstr Surg. 1970;45(6): 573-577.

50. Cronin TD, Greenberg RL. Our experiences with the silastic gel breast prosthesis. Plast Reconstr Surg. 1970;46(1):1-7.

51. Virden CP, Dobke MK, Stein P, Parsons CL, Frank DH. Subclinical infection of the silicone breast implant surface as a possible cause of capsular contracture. Aesthetic Plast Surg. 1992;16(2):173-179.

52. van Heerden J, Turner M, Hoffmann D, Moolman J. Antimicrobial coating agents: can biofilm formation on a breast implant be prevented? J Plast Reconstr Aesthet Surg. 2009;62(5):610-617.

53. Deva A, Chang L. Bacterial biofilms: A cause for accelerated capsular contracture? Aesthetic Surgery Journal. 1999;16:130-133.

54. Shah Z, Lehman JA Jr, Tan J. Does infection play a role in breast capsular contracture? Plast Reconstr Surg. 1981;68(1):34-42.

\section{Medical Devices: Evidence and Research}

\section{Publish your work in this journal}

Medical Devices: Evidence and Research is an international, peerreviewed, open access journal that focuses on the evidence, technology, research, and expert opinion supporting the use and application of medical devices in the diagnosis, treatment and management of clinical conditions and physiological processes. The identification of novel
55. Schreml S, Heine N, Eisenmann-Klein M, Prantl L. Bacterial colonization is of major relevance for high-grade capsular contracture after augmentation mammaplasty. Ann Plast Surg. 2007;59(2):126-130.

56. Pajkos A, Deva AK, Vickery K, Cope C, Chang L, Cossart YE. Detection of subclinical infection in significant breast implant capsules. Plast Reconstr Surg. 2003;111(5):1605-1611.

57. Macadam SA, Clugston PA, Germann ET. Retrospective case review of capsular contracture after two-stage breast reconstruction: is colonization of the tissue expander pocket associated with subsequent implant capsular contracture? Ann Plast Surg. 2004;53(5):420-424.

58. Heidrich M, Kühnel MP, Kellner M, et al. 3D imaging of biofilms on implants by detection of scattered light with a scanning laser optical tomograph. Biomed Opt Express. 2011;2(11):2982-2994.

59. Elter C, Heuer W, Demling A, Hannig M, Heidenblut T, Stiesch M. Comparative analysis of biofilm formation on dental implant abutments with respect to supra- and subgingival areas: polytetrafluoroethylene versus titanium. Int J Prosthodont. 2011;24(4):373-375.

60. Lindel ID, Elter C, Heuer W, et al. Comparative analysis of longterm biofilm formation on metal and ceramic brackets. Angle Orthod. 2011;81(5):907-914.

61. Bremer F, Grade S, Kohorst P, Stiesch M. In vivo biofilm formation on different dental ceramics. Quintessence Int. 2011;42(7):565-574.

62. Pfaffenroth C, Winkel A, Dempwolf W, et al. Self-assembled antimicrobial and biocompatible copolymer films on titanium. Macromol Biosci. 2011;11(11):1515-1525.

63. Heuer W, Kettenring A, Stumpp SN, et al. The microbial diversity of periimplant biofilms on implant fixed bar- and telescopic double crown attachments. J Oral Implantol. Epub February 18, 2011.

64. Dobke MK, Svahn JK, Vastine VL, Landon BN, Stein PC, Parsons CL. Characterization of microbial presence at the surface of silicone mammary implants. Ann Plast Surg. 1995;34(6):563-569.

65. Poeppl N, Schreml S, Lichtenegger F, Lenich A, Eisenmann-Klein M, Prantl L. Does the surface structure of implants have an impact on the formation of a capsular contracture? Aesthetic Plast Surg. 2007;31(2): 133-139.

66. Tamboto H, Vickery K, Deva AK. Subclinical (biofilm) infection causes capsular contracture in a porcine model following augmentation mammaplasty. Plast Reconstr Surg. 2010;126(3):835-842.

67. Rennekampff HO, Exner K, Lemperle G, Nemsmann B. Reduction of capsular formation around silicone breast implants by D-penicillamine in rats. Scand J Plast Reconstr Surg Hand Surg. 1992;26(3):253-255.

68. Unlu RE, Yilmaz AD, Orbay H, Can B, Tekdemir I, Sensoz O. Influence of rifampin on capsule formation around silicone implants in a rat model. Aesthetic Plast Surg. 2007;31(4):358-364.

69. Helmus MN, Gibbons DF, Cebon D. Biocompatibility: meeting a key functional requirement of next-generation medical devices. Toxicol Pathol. 2008;36:70-80.

70. Gryskiewicz JM. Investigation of accolate and singulair for treatment of capsular contracture yields safety concerns. Aesthet Surg J. 2003;23(2): 98-101.

71. Laschke MW, Vollmar B, Menger MD. The dorsal skinfold chamber: window into the dynamic interaction of biomaterials with their surrounding host tissue. Eur Cell Mater. 2011;22:147-167.

72. Williams DF. On the mechanisms of biocompatibility. Biomaterials. 2008;29(20):2941-2953.

73. Baker Jr JL: Augmentation mammaplasty. In: Owsley Jr JQ, Peterson RA, editors. Symposium on Aesthetic Surgery of the Breast. St Louis: Mosby; 1979.

\section{Dovepress}

devices and optimal use of existing devices which will lead to improved clinical outcomes and more effective patient management and safety is a key feature. The manuscript management system is completely online and includes a quick and fair peer-review system. Visit http://www. dovepress.com/testimonials.php to read real quotes from authors. 